\title{
Behind the emergence of clusters: spinoffs and social ties. The case of an Italian industrial district
}

\author{
Christian Garavaglia \\ Department of Economics, Management and Statistics (DEMS), \\ University of Milano-Bicocca, \\ Piazza dell'Ateneo Nuovo 1, 20126, Milan, Italy \\ and \\ The Invernizzi Center for Research on Innovation, Organization, \\ Strategy and Entrepreneurship, \\ Bocconi University, \\ Via Roentgen 1, 20136, Milan, Italy \\ Email: christian.garavaglia@unimib.it
}

\begin{abstract}
The traditional economic literature explains the process of geographic agglomeration of firms with regard to the existence of external economies or agglomeration economies. The purpose of this paper is to investigate an alternative view, following some more recent influential studies about spinoffs and the emergence of clusters (Boschma, 2015). We discuss how the joint processes of spinoffs, knowledge inheritance and social ties may shape the emergence of firms in a cluster without referring to the existence of external economies. This paper presents the case of the industrial swimwear district in Oleggio, Italy and provides evidence that the formation of spinoffs and social ties contributed to the emergence of the district.
\end{abstract}

Keywords: cluster; industrial district; spinoff; social ties; knowledge inheritance; external economies; regional development; swimwear.

Reference to this paper should be made as follows: Garavaglia, C. (2018) 'Behind the emergence of clusters: spinoffs and social ties. The case of an Italian industrial district', Int. J. Innovation and Regional Development, Vol. 8, No. 1, pp.23-43.

Biographical notes: Christian Garavaglia is an Assistant Professor at the Department of Economics Management and Statistics (DEMS), University of Milano-Bicocca, and research affiliate at the Invernizzi Center for Research on Innovation, Organization, Strategy and Entrepreneurship (ICRIOS), Bocconi University. He received his $\mathrm{PhD}$ in Economics from the University of Pavia and his MSc in Economics from the University of York. His research interests include industrial organisation, industrial dynamics, industrial districts and clusters, consumer preferences for food, and brewing industry.

\section{Introduction}

Different strands of literature explain the process of geographic agglomeration of firms. The traditional frameworks relate the process of clustering of firms in a given localised and geographically defined area to the existence of external economies or agglomeration 
economies. According to the traditional explanations, once a new activity begins to be located in a region, the existence of external benefits fosters new firms to settle there, becoming the engine of the emergence of so-called clusters or industrial districts.

This work follows a different route and provides an alternative explanation. The research question of this paper is whether we can explain the emergence of clusters and industrial districts not by referring to the existence of external agglomeration economies but by focussing on the joint forces related to the formation of spinoffs and social ties. Spinoffs refer to new firms founded by employees of existing firms. Some recent studies have emphasised how, under certain conditions, spinoffs are able to explain cluster development without referring to the existence of agglomeration economies (Sorenson, 2003; Klepper, 2008, 2010; Buenstorf and Klepper, 2009; Buenstorf and Fornahl, 2009; Buenstorf and Guenther, 2011). This paper aims at providing further evidence in support of these dynamics. We carry out an original field study through survey questionnaires to gather microeconomic evidence on the links between the evolution of clusters and the role of spinoffs and prior knowledge, focusing on the case of the Italian swimwear industrial district in Oleggio (Novara). Our results provide new original evidence in support of the importance of spinoffs in cluster formation, the role of knowledge inheritance in determining the activities of new ventures in the cluster and the function of social ties in influencing entrepreneurs' location decisions.

In what follows, we first discuss the main contributions in the literature about the role of external economies (Section 2). Then, we analyse the theory of spinoffs and social ties and construct our hypotheses (Section 3). Finally, we discuss the case study of the swimwear industrial district in Oleggio (Section 4). Section 5 concludes.

\section{Relevant literature: external economies and the geographic agglomeration of firms}

The question of why firms cluster geographically is old. In this section, we do not intend to provide a comprehensive overview of the literature. In contrast, we aim to discuss the main traditional approaches in the economic literature on the formation of clusters (and industrial districts). The development of industrial clusters has been traditionally widely analysed and discussed in a Marshallian spirit (Marshall, 1920, 1919). The existence of some kind of positive external economies has always been the main explanation of the emergence and growth of clusters. The development of a cluster is comparable to a social organisation whose evolution brings, on the one hand, increasing specialisation, production flexibility and differentiated functions and, on the other, a stronger and more intimate interrelation among its parts and functions. This creates positive economies that are external to the firms but internal to the local industrial system such that firms are able to exploit collective economies of scale. Thus, the Marshallian tradition emphasises the effects of the availability of skilled and specialised workforce, the localisation of specialised suppliers and the ease of transmission of knowledge and information flows in a given area. A geographically concentrated industry is able to offer highly skilled human capital such that firms, which want to be located in a local area where it is likely to find the special skilled workforce they need, find it advantageous to locate themselves close to other existing firms. Similarly, trained and skilled employees move to areas where employers look for such specific skills and customer firms and suppliers gain by locating themselves close to each other because of transportation cost savings. Moreover, the 
mysteries of trade are in fact no mystery and knowledge is in the air, according to the well-known Marshallian metaphor; firms can take advantage of knowledge diffusion by locating themselves close to other firms. These processes, once at work, are self-reinforcing and generate a mechanism of cumulative causation and 'dynamic vertical disintegration' (Scott, 1988).

This basic argumentation has been used and further developed by different researchers to stress the importance of different aspects.

The Italian theories of industrial districts strictly developed along the Marshallian tradition. The merit of these studies is further developing a more critical and 'productive' role for socioeconomic and cultural aspects in influencing the emergence and growth of the cluster (Becattini, 1987, 1989, 1990, 2002; Brusco, 1989; Sforzi, 1990). The individuals, the local knowledge and the system of values become in this view a factor of production, as classical economic factors are. Industrial districts are, thus, defined as a socio-territorial entity characterised by the coexistence of a community of people with a sufficient cultural complexity and a set of firms in a well-specified area (Becattini, 1989) with a shared system of values, thoughts, views, language, expectations and behaviours combined with a local entrepreneurial culture and knowledge, which shape the industrial atmosphere and facilitate the relationships among firms, people and institutions. Economic factors and socio-cultural aspects fuse into a unique conceptual framework: a block of economic and production relationships and a block of socio-cultural processes are both spatially defined. The two overlap and interrelate with each other. In this context, public institutions and private organisations contribute to enforcing these mechanisms (Molina-Morales and Martinez-Fernàndez, 2008).

A crucial condition for the rise of this division of activities and integration of relationships is given by the emergence of a demand for new differentiated and personalised goods and services. These conditions follow the emergence of a new set of needs with social and qualitative content, developed in large segments of the middle class, who aim at new differentiated and sophisticated goods to show social status and prestige (Becattini, 2002). This shift from manufacturing standard products to more differentiated and refined goods gives a more important role to the external economies and the coordinating relationships among individuals and firms. It comes out a figure of a local area where the local structures of the social community and institutions increase the willingness and the opportunities to become self-employed (Bagnasco and Trigilia, 1984, 1985; Becattini, 1997; Lin et al., 2006). The local system that emerges from this picture is a community in which the spirit of 'entreprendre' is vivid, the cultural beliefs are supportive to new business formation and self-employment and behaviours and mobility inside the area favour the development and diffusion of technical know-how, creativity, skills, organisational capacity and entrepreneurial attitude, such that the outcome of these socio-economic processes is given by an 'enlarged family' of small entrepreneurs and self-employed people who share the same experience and set of values.

Small firms in particular lack the resources of large firms and are thus more dependent on resources in their local environment (Feldman and Francis, 2003, 2004). In industrial clusters, small firms are able to overcome their size disadvantages (Pyke and Sengenberger, 1990). The reason may find its explanation in the existence of local knowledge spillovers from which small firms in a cluster may benefit. We refer to local knowledge spillovers as positive knowledge externalities bounded in space coming from the spread of ideas and activities among economic agents, which generate further 
opportunities for other agents located in the same area. The role of knowledge spillovers has received much attention in the last few years (Breschi and Lissoni, 2001). Networks of economic agents that interact with each other represent the source of agglomeration and knowledge spillovers, which, in turns, positively foster urban development, the rate of innovative activities (Audretsch, 2003) and technology transfer (Spithoven, 2015). Knowledge relevant for innovative and entrepreneurial activities is mostly tacit and needs personal face-to-face contact and labour mobility to transmit and these factors are more likely to occur locally. The externalities related to the existence of knowledge spillovers originating from firms within the same industry have been considered the 'engine of growth' for regions and cities (Romer, 1996; Lucas, 1988) and have been widely discussed following the studies acknowledged as Marshall-Arrow-Romer (MAR) externalities (Glaeser et al., 1992). Knowledge is considered a crucial input that endogenously creates technological opportunities for growth (Acs et al., 2009). The works of Porter (1990) also discuss the role of knowledge spillovers in specialised, geographically concentrated industries in fostering growth, emphasising the importance of local competition among firms in common industries as a source of innovation and productivity (Glaeser et al., 1992; Bun and Makhloufi, 2007; Groot et al., 2014). ${ }^{1}$

The empirical evidence on knowledge spillovers is ambiguous. Some contributions (Breschi and Lissoni, 2001; Gordon and McCann, 2000) note the overestimation of knowledge spillovers in explaining cluster formation. The most important point to note is that most of the econometric literature that has attempted to estimate the existence and magnitude of localised knowledge spillovers has not been able so far to shed light on the actual mechanisms through which knowledge is transmitted among agents. As a consequence, most of the results obtained regarding the spatial concentration of innovative and entrepreneurial activities might be observationally equivalent to other explanations, particularly to those that neglect any importance of knowledge spillovers and note the role of more traditional market-based pecuniary externalities arising in the labour market and in the market for intermediate inputs.

Differently from the knowledge spillovers sustainers, the contributions of the so-called 'new economic geography' (Krugman, 1991a, 1991b; Puga and Venables, 1996; Ottaviano and Thisse, 2001) explain the processes of the geographic concentration of firms on the basis of pure pecuniary externalities related to the labour market and to the demand side. The level of transport costs, the increasing returns to scale at the plant level and factor mobility, involving a circular causation mechanism, play a critical role in triggering the process of agglomeration of firms. The emergence of clusters is explained as a cumulative and self-reinforcing process in which the location of new firms in a region attracts workers from other areas to benefit from relatively higher wages, this, in turn, stimulates the further entry of new firms in the same region to benefit from a larger local market and save on transport costs. The basic point to stress in this cumulative process is that the emergence of clusters is entirely explained on the basis of the locational choices made by entrepreneurs and that non-market external economies, such as knowledge spillovers, do not play any role in driving such locational choices. According to this view, the formation of clusters is given with regard to pure economic explanations. The existence of external pecuniary economies is able to endogenously explain firms' agglomeration independently on the exogenous natural and physical characteristics of the location (Ottaviano and Puga, 1998; Rosenthal and Strange, 2004; Ottaviano and Thisse, 2001). More formally, the original family of models of the so-called 'new economic geography' assumes the existence of two identical regions, two 
sectors (manufacturing producing under returns to scale technology and agriculture producing under constant returns to scale) and two types of input, one of which is employed in manufacturing and is mobile across regions (workers) and the other of which is utilised in agriculture and is immobile (land). A greater number of producers in a region implies a greater number of product varieties produced and consequently a rise in the demand for labour and wages, inducing workers to move to this region. The concentration of workers (who are also consumers) generates a larger market in this region (the so-called 'home market effect'). Because of economies of scale and transport costs, producers benefit from concentrating the production in only one region and shipping the product to the other. Forward linkages due to the incentive for workers to be where the producers of final goods are located and backward linkages that represent the incentive of producers to cluster in the larger market create a centripetal force that ends up in firms and workers clustering in a region (Krugman and Venables, 1990; Krugman, 1991a, 1991b; Ottaviano and Puga, 1998; Ottaviano and Thisse, 2001, 2004). According to this line of research, the essence of cluster formation is then given by the existence of these pecuniary externalities, whereas other non-pecuniary factors are believed to be too vague (Krugman, 1991a).

The elegance of the logic and models of the 'new economic geography' supporters had to address the criticism of this strain of research lacking corresponding empirical relevance. Moreover, the empirical support of the 'new economic geography' is questioned if it is not considered that spatial scale economies materialise only after firms make their location decisions accordingly.

In summary, the approaches presented in this section share a common feature in explaining the development of clusters: some sort of external benefit that network firms are able to appropriate when located in the cluster triggers the process of agglomeration of firms.

\section{Theory and hypotheses}

In this section, we discuss an alternative theory of the emergence of clusters without depending on external agglomeration economies. Following the arguments of some researchers (Sorenson, 2003; Klepper, 2008; Buenstorf and Klepper, 2009; Buenstorf and Fornahl, 2009; Buenstorf and Guenther, 2011), we centre the analysis, first on spinoffs and knowledge inheritance in Section 3.1 and, second, on social ties and networks in Section 3.2. In what follows, we focus on the definition of clusters as a geographical area where many actors are located and operate in related industries. This definition requires at least two ingredients:

a actors engaged in 'related activities'

b actors located in the 'same geographical area'.

\subsection{Spinoffs formation}

The US automobile industry was geographically dispersed initially and over time it evolved to be highly concentrated around only one city, Detroit. In contrast, in the US television industry, since its beginning, most of the firms have been clustered around 
New York, Chicago and Los Angeles. After some years, the industry became more concentrated in terms of market structure but more geographically dispersed. Neither of these two patterns of evolution provides support for the existence of external agglomeration forces that enhance the performance of firms located there. If there were positive agglomeration effects in the television industry, then, the deagglomeration processes in New York and Los Angeles would have stopped and Chicago would have become the leading city. In addition, with regard to automobiles, there was no evidence of an advantage for locating in Detroit, which in the end became the centre of the industry.

An alternative explanation is proposed by Klepper (2008), who focuses on the inheritance of organisational competences from parent firms to spinoffs: we call this process knowledge inheritance. Pre-entry experience is crucial for entrepreneurs' subsequent decisions (Helfat and Lieberman, 2002). The explanation starts from the assumption that knowledge of particular routines and specific technologies accounts for a large proportion of the heterogeneity across firms in profitability and performance. Replicating this scarce and valuable knowledge may be extremely difficult, if not impossible, for potential entrepreneurs, whose background is in a different business line or who plan to found a start-up company. In contrast, entrepreneurs coming from related industries or from the incumbents in the industry are likely to inherit from their pre-entry experience some of the organisational competences of the originating companies. There is something tacit in knowledge and competences that it is difficult to learn without experiencing first hand (Klepper, 2011). Incumbent firms play the crucial role of providing natural training for the spinoff firms originating from them, determining their prior knowledge before their entry occurs. ${ }^{2}$ Those entrants who have access to the knowledge and capabilities, then, potentially enjoy an advantage over other firms. If one accepts the idea that the most competent entrants in an industry are those founded by entrepreneurs who were former employees of firms in the same or in a related industry, then it is possible to explain the birth of new waves of firms engaged in the same activity of the 'parent' firm. Spinoff processes increase the transfer of knowledge, routines and learning and the number of firms operating in activities related to the parent firms. This dynamics implies that the most successful incumbent firms pass on their knowledge and competencies to a new generation of spinoff firms that operate in the same activities. Therefore, given a successful incumbent (or few incumbent firms), "if the distribution of employees in terms of their ability to organise a spinoff was the same at all incumbent firms, then employees in better firms would be more likely to found (profitable) spinoffs and to have (i.e., more profitable) spinoffs. This prediction would be reinforced if better firms also had more able employees. If employees locate their spinoffs close to their prior location, this could lead to a build-up of successful spinoff firms around successful early entrants, giving rise to clustering" (Klepper, 2011). We turn to the decision of location in the next section (Section 3.2).

Some empirical works support this view. Buenstorf and Klepper (2009) analyse the US tyre industry, investigating the factors that induced the industry to be regionally clustered around Akron. Akron is a small city in Ohio with no particular advantages for tyre production. The results show that the geographic concentration of firms around Akron was driven not by the existence of agglomeration economies that attracted entrants in this area but by a process of reproduction and heredity induced by the creation of new entrants, spurred by the supply of entrepreneurs. Buenstorf and Fornahl (2009) analyse the emergence of a software cluster in Germany, ascribing its birth to a process of 
spinning off of many small new firms, generated by the downsizing of the large parent firm Intershop. These new ventures established locally give rise to a concentration of firms around Jena. The spinning off of firms from a public institution (ITRI) in Taiwan generated a successful cluster in the computer and microchip industry in Hsinchu (Parker, 2010). Other empirical evidence is found in the automobile industry in the UK (Boschma and Wenting, 2007), the laser industry in the USA (Klepper and Sleeper, 2005), the disk drive industry in the USA (Franco and Filson, 2006), the semiconductor industry in Silicon Valley (Saxenian, 1983), the musical instrument cluster in Italy (Tappi, 2005), the plastic district in Italy (Patrucco, 2005), the laser industry in Germany (Buenstorf, 2007) and the call centre cluster in Sweden (Nuur and Laestadius, 2010).

The spinoff and knowledge inheritance argument suggest the following hypotheses:

Hypothesis 1 The number of firms in a cluster proliferates through spinoff processes.

Hypothesis 2 Founders inherit the competencies from their previous work experience and implement these competencies in their new entrepreneurial venture in the same activity.

So far, we have analysed the birth of new firms in a cluster engaged in the same activities. We now turn our attention to what we call ingredient (b): spinoffs tend to be locate in the 'same geographical area' as their parent firms.

\subsection{Social ties and social network}

The second ingredient for a cluster is given by geographical agglomeration. The crucial force here relates to the role of social ties and local network in influencing the decision of where to locate a new firm (in our case, spinoff), even in the absence of locational effects (Sorenson, 2003; Stuart and Sorenson, 2003; Sorenson and Audia, 2000).

Spinoffs, as well as other entrepreneurial activities, require the mobilisation and the organisation of the resources necessary to start a new firm. In this respect, geography and location matter because they help in establishing and maintaining those network ties that are vital to mobilise the resources needed to found a new venture.

In the first place, social ties affect the awareness of entrepreneurial opportunities. Evaluating market opportunities is often a first step in the entrepreneurial process and it requires access to private information and data (Garavaglia and Breschi, 2009). Social linkages represent a powerful means to access these valuable data. Once an opportunity has been identified, social networks also constrain where individuals can successfully build new firms. In fact, the success of a new company depends on having access to some key factors, notably human capital, financial capital, knowledge capital and trust. Given the high risks involved and the fundamental information asymmetry problem afflicting new ventures, entrepreneurs may find it difficult to collect sufficient financial and human capital (Granovetter, 1973, 2005). Strong and dense social ties help to overcome this constraint by reducing the amount of uncertainty and by raising the trust necessary to convince investors and potential employees about the real prospects of the nascent firm.

Typically, these aspects cannot be easily replicated outside the local community, outside the geographically bounded area of the cluster (Figueiredo et al., 2002). An important consequence of this perspective on entrepreneurship and clustering is that locational inertia is likely to emerge. The need to draw on social networks to identify entrepreneurial opportunities and to mobilise financial and labour resources, together 
with the fact the individuals prefer to remain close to family and friends, which tends to bind potential entrepreneurs to the regions in which they have contacts, i.e., the regions in which they have worked and lived, even though other locations may seem more attractive. This implies that once clustered in a given location, an industry tends to remain persistently located in the same area, even when co-location implies disadvantages, as evidenced by Figueiredo et al. (2002).

Therefore, social ties theory suggest the following hypothesis:

Hypothesis 3 Spinning-off entrepreneurs are bounded by social ties and locate themselves in the same cities where they already have contacts and live.

\subsection{Spinoffs 'plus' social ties: the spinoff theory of industry clustering}

The picture that emerges in this section can be summarised as follows. In the formative stage of an industry, a geographic area is characterised by the primitive existence of some firms (because of availability of natural resources, historical accidents or other reasons). The most successful firms generate spinoffs and spinoffs inherit knowledge from their parent firms (Klepper and Sleeper, 2005). This force is combined with the fact the individuals prefer to remain close to family and friends and usually draw on social networks to identify entrepreneurial opportunities and to mobilise financial and labour resources. Therefore, spinoffs tend to display 'sticky' behaviours by inducing spinning-off entrepreneurs to locate themselves in the cities and regions in which they already live. Because these spinoffs settle in the same geographic area of the parent firms, a cluster emerges. The conclusion is that clusters may develop thanks to the locational inertia of the spinoff firms that operate in the same geographical area and in the same activity as the parent firm, without referring to the existence of any external or agglomeration economies.

However, the argument of spinoff theory of industry clustering is alternative but not mutually exclusive to the external economies explanation, as discussed by Boschma (2015). The specificity of an industry may play a role and external economies cannot be entirely excluded in the reasoning. External economies may play a role both in the emergent stage of cluster formation because of local related industry specificities and in the subsequent stages when the cluster has already been developed. In addition, firms may find benefits in exploiting the specialisation of suppliers, knowledge spillovers, the availability of skilled and specialised workforce and the active role of the institutions.

\section{Case study: the Oleggio swimwear district in Italy}

Many studies analyse industrial districts by aggregating large datasets on different districts together (Paniccia, 2002). An alternative methodology consists of collecting more precise micro data about a single case: in this way, the research can cover various aspects related to specialisation in production, the cultural background of the entrepreneurs and other micro data, giving a more complete analysis of the features that characterise the district. In this section, we discuss the case of the Oleggio industrial district. The purpose of this section is to assess the following questions, in accordance with the hypotheses developed in Sections 3.1 and 3.2 as suggested by the theories: Have the firms of the Oleggio district proliferated through spinoffs? Have the founders of firms 
inherited competencies from their previous work experiences? Have the spinning-off firms of the district displayed locational inertia?

Figure 1 Specialisation of municipalities in the Oleggio and Varallo Pombia districts (see online version for colours)
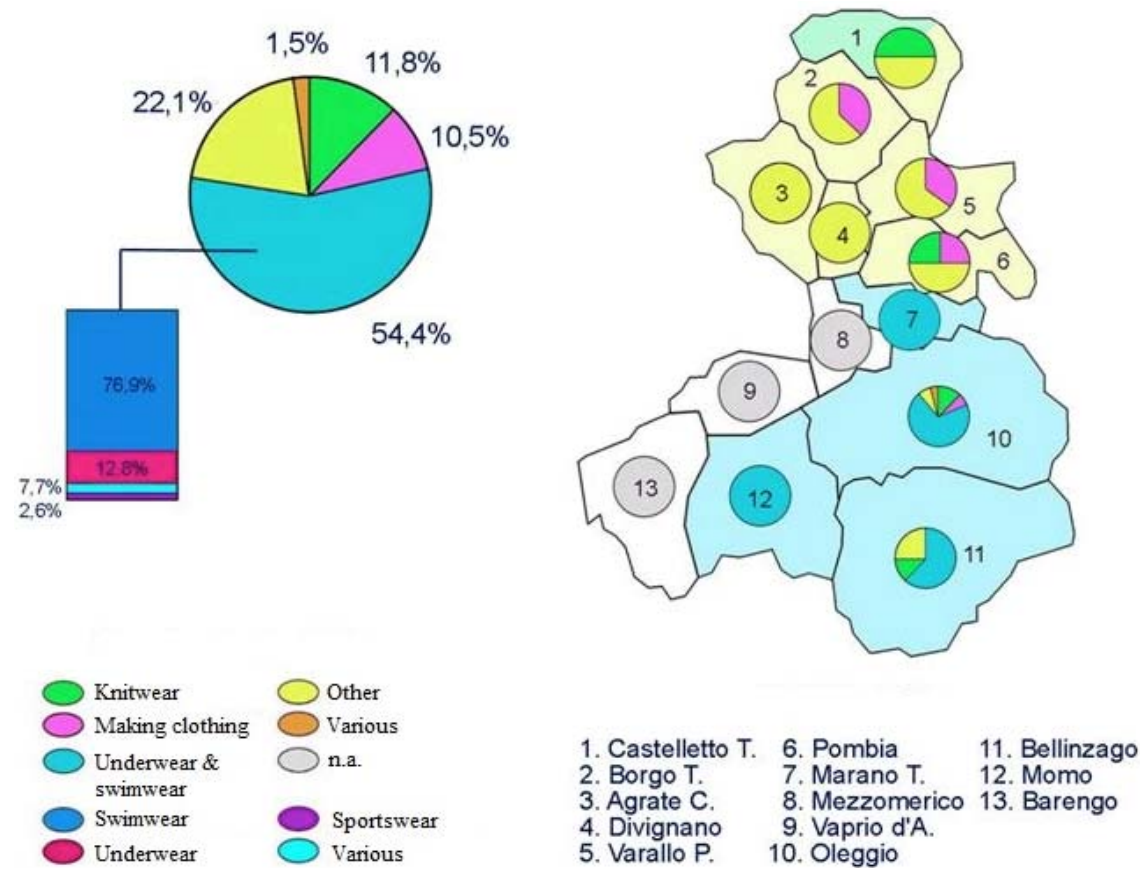

Note: The Varallo Pombia district accounts municipalities from one to six, the Oleggio district accounts for municipalities seven to 13 .

Source: Baici and Mainini (2003), Mainini (2003)

Oleggio is a small town (approximately 11.5 hundreds inhabitants in 1996), located in the northeastern territory of Novara, along the boundary between Piedmont and Lombardy in the North of Italy. The regional government recognises Oleggio as one of the local industrial districts in Piedmont that combines seven municipalities ${ }^{3}$ (delibera n. 227-6665, 26 February 2002), specialising in textiles, accompanied by the presence of a parallel mechanical sector. In particular, Oleggio is characterised by a high level of specialisation in swimwear and underwear manufacturing, as is shown in Figure 1. Close to Oleggio and closely related to Oleggio's activities, another district emerged, centred on the town Varallo Pombia. The Varallo Pombia industrial district combines six municipalities and specialises in mechanics and textiles as well (Figure 1).

The formative stage of the textile industry in Oleggio dates back in 1885, when the entrepreneur Giovanni Gagliardi established a successful firm, named Gagliardi, for the manufacturing of corsets, corsetry and related tissues in Oleggio. In a few decades, this firm became the main manufacturing establishment in the area, with several hundreds of employees. The swimsuits first appeared in local production only after World War 2 in the late '40s-early ' $50 \mathrm{~s}$, when this product became part of the goods of mass consumption. The other successful leading firm dedicated to the production of swimsuits, 
manufacturing Gagliardi Oleggio (MGO), dates back to those years. These two firms embody the birth of the swimwear industrial industry in the province of Novara. In the '60s-'70s, Gagliardi and MGO grew and prospered and many micro and small firms, often with fewer than 20 employees, were founded, operating as contractors. Many small firms originated from these larger incumbents either by the deliberate strategy of incumbents to create subcontractors or by the process of spinoffs of former employees. In addition, many new firms were created because of cases of factories' closures and downsizing.

Over the years, some of these micro firms expanded and became producers on their own, whereas many others remained subcontractors. Many firms in the district also attempted to diversify their production by offering corsetry, lingerie and sportswear, trying to overcome the seasonal nature of the production of swimwear. A good image; a strong relationships with clients in Europe, particularly in Germany, the presence of highly qualified and skilled labour and entrepreneurs that were able to capture the market and stimulate demand and create innovations were the principal factors that ensured the competitiveness of the sector and the success of many firms in the district in the international markets (Baici and Mainini, 2003).

Table 1 Industrial district indexes in Oleggio according to the Italian law DM 21/04/93: 1981-1991

\begin{tabular}{lccc}
\hline \multirow{2}{*}{ Index } & Required value & \multicolumn{3}{c}{ Oleggio } \\
\cline { 3 - 4 } & & 1981 & 1991 \\
\hline $\mathrm{Im}$ & $>1.3$ & 1.82 & 1.93 \\
$\mathrm{Id}$ & $>1$ & 1.43 & 1.51 \\
$\mathrm{Is}$ & $>1.3$ & 1.96 & 2.07 \\
$\mathrm{Ps}$ & $>0.3$ & 0.42 & 0.42 \\
$\mathrm{Pi}$ & $>0.5$ & 0.64 & 0.80 \\
\hline
\end{tabular}

Source: Baici and Mainini (2003) on Istat data

This process of development induced regional legislation to recognise the area around Oleggio as an industrial district. With the Ministerial Decree of 21 April 1993, the required conditions to define an industrial district were made more explicit and parameterised by identifying some operational rules and indicators for the delimitation of an industrial district organisation. These conditions are related to some quantifiable indexes: the index of manufacturing industrialisation $(\mathrm{Im})^{4}$, the index of entrepreneurial density (Id), the index of specialisation (Is), the weight of the sector (Ps) and the incidence of employment in small firms (Pi). Table 1 clearly shows that the area of Oleggio matched all the required values of the indexes and therefore it is eligible to be considered an industrial district.

The district is characterised, as in many other Italian cases, by a high degree of heterogeneity in terms of product differentiation, firm size and forms of production. It is possible to recognise the presence of a large group of small firms and a handful of medium-large producers, focussed on the production of swimwear and sports clothing. Firms are mainly localised in two towns: Oleggio and Bellinzago Novarese. The number of firms, as well as the number of employees, have decreased since the nineties due to the process of international competition that intensified during the ' 80 s and ' 90 s (Figure 2): this trend has generally characterised the entire province of Novara (Figure 3). 
Figure 2 Evolution of the number of firms in the municipalities of the Oleggio district between 1991 and 2001

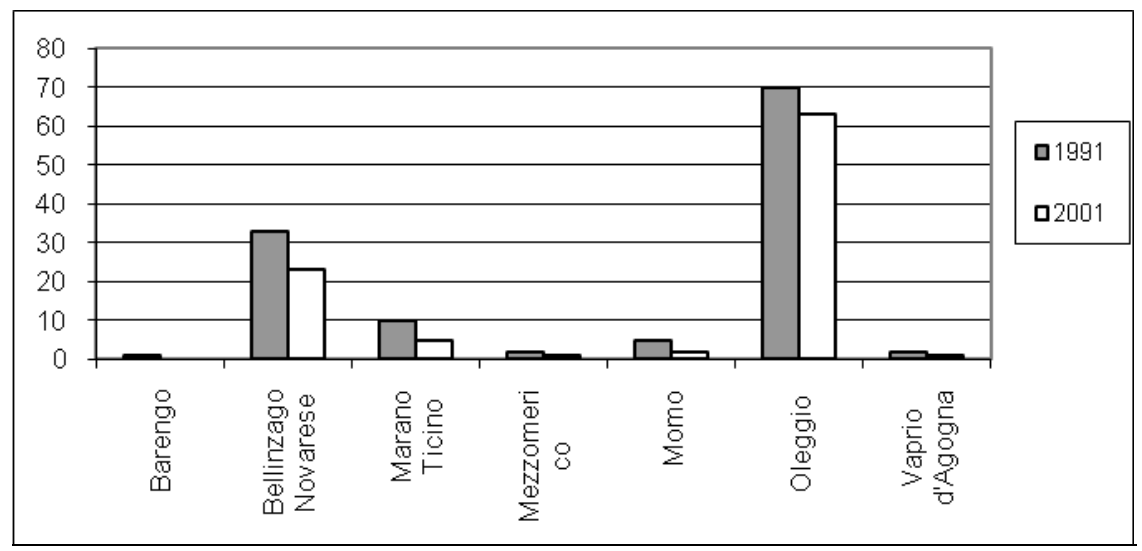

Source: Istat 1991, 2001

Figure 3 Number of firms from 1971 and 2001 (Ateco code 182)

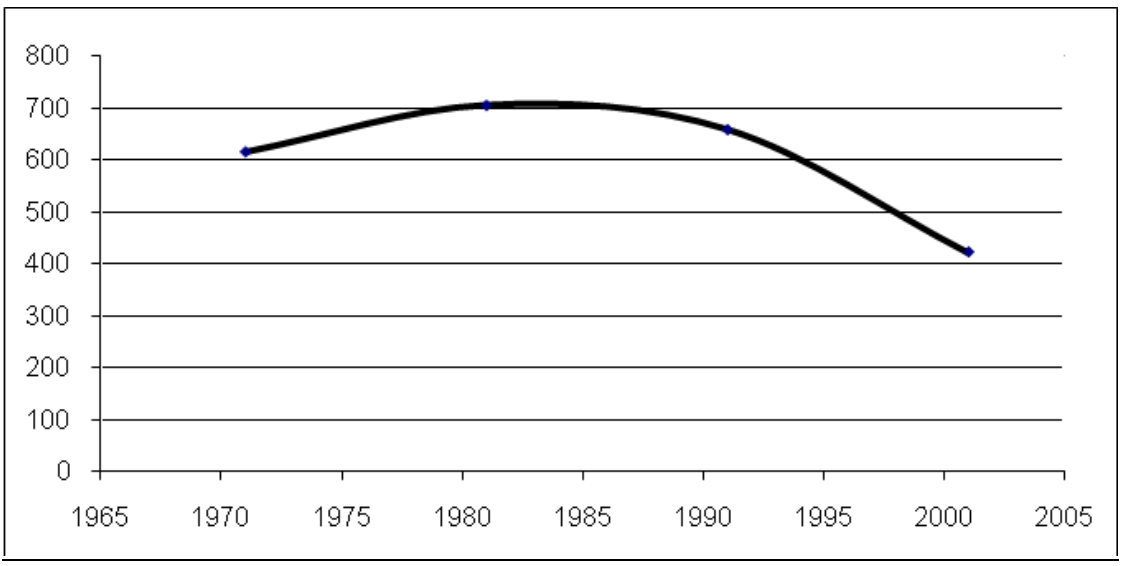

Source: Istat 1971, 1981, 1991, 2001

Baici and Mainini (2003) claim that this situation of crisis should also be ascribed to the fact that Oleggio is not really an effective industrial district but only a sort of 'district of fact' defined by indexes, business characteristics and economic variables that in practice lacks effective cooperation among firms, knowledge transfer and mutual support that usually characterise industrial districts. The majority of the interactions between firms appear to be limited to a simple direct relationship of subordination, without providing specific forms of mutual cooperation or contributions among firms, whereas the spirit of competition tends to remain very high, generating a general attitude of uncertainty and distrust. In support to this criticism, Baici and Mainini mention the failure of only example of cooperation among firms in the area: the creation of the Società Consortile Promozione e Sviluppo Distretto Ticino in 1998 (Ticino District Promotion and Development Consortium), by the initiative of the Chamber of Commerce of Novara, the Novara Industrial Association and the Association of Small and Medium Enterprises with 
the intent of benefitting from the contributions provided by regional law n. 24/97 to support the growth of the district. The authors conclude that Oleggio might be considered not as a real district structure but rather as a simple localised concentration of firms operating in the same productive field.

It is not the purpose of this paper to discuss if Oleggio can be considered a real district. We are interested in the formation of the cluster of firms in the Oleggio area, with the intent of investigating if spinoffs drove the clustering process. We develop this analysis in the following section.

\subsection{Data and methodology}

The methodology of our analysis is organised in three steps. First, we interviewed some experts of swimwear manufacturing to understand the main characteristics of production and work organisation. These meetings allowed us to compose a questionnaire to submit to existing firms in the district. The questions are mainly closed questions, which results in a minimal loss of time by the interviewee and in an immediate quantitative analysis of individual responses.

Table 2 Number of firms in the Oleggio district in 2007

\begin{tabular}{lc}
\hline Municipality & $N^{o}$ firms 2007 \\
\hline Barengo & 0 \\
Bellinzago Novarese & 13 \\
Marano Ticino & 4 \\
Mezzomerico & 0 \\
Momo & 3 \\
Oleggio & 35 \\
Vaprio d'Agogna & 0 \\
Total & 55 \\
\hline
\end{tabular}

Source: Author's elaborations

Second, we identified 55 active firms in 2007 in the district area through the online 'Registro delle Imprese' (i.e., the register of firms), the internet, phone calls and personal visit, as reported in Table 2. Then, we submitted the questionnaire to a subsample of these firms, randomly selected according to a stratified sampling method. Of the 55 firms in the territory, 43 of these were proposed to participate to the research project.

The questionnaire submission was organised through a preliminary phone call to explain the research project to the interviewee and subsequent data collection through a meeting or emailing or fax, according to the interviewees' preferences. Thirty-four of these firms declared to be willing to participate, but in the end, only 19 responded $(34.5 \%$ of the entire population).

Third, we organised the data of our case study to assess our research questions, developing a qualitative analysis (the limitations of the data do not allow us to implement an econometric investigation).

The questionnaire had the objective to obtain information about the founder and the firm at the year of foundation (we refer to this as the 'new firm'); the firm where the founder was previously employed, if applicable (we refer to this as the 'parent firm'); and 
the activity of the 'new firm' in the present years. The crucial information on which the research focuses is related to the following questions:

- information about the parent firm(s) where the founder(s) was previously employed

- the production field of the parent firm(s) where the founder(s) was previously employed (e.g., knitwear, sportswear, swimwear, corsetry, furs, etc.)

- the work activity of the firm(s) where the founder(s) was previously employed (e.g., sewing, drawing, embroidery, carding, cutting, dyeing)

- if the new firm started by the founder(s) was a subcontractor

- if the founder was previously an entrepreneur

- the production field of the firm started by the founder(s)

- if the firm started by the founder(s) specialises in any activity of the production chain.

\subsection{Analysis and discussions}

The data we collected enabled us to understand the process of development of firms in the Oleggio district to assess our research question related to cluster formation. In particular, the questionnaire asks the interviewees to trace back their work career such that we are able to reconstruct if the founder had previously been employed in another firm working in the same area and in the same manufacturing field and in what activity he/she was specialised.

The results of the qualitative analysis present interesting insights for our purposes. Our data show that firms mainly started as spinoffs: $73.6 \%$ of our sample was created as a spinoff. This would confirm Hypothesis 1, as discussed in Section 3.1. This result leads us to believe that the vast majority of the number of firms in the cluster proliferated through spinoff processes.

Another key result refers to the skills and competences developed by the founders: $85.7 \%$ of respondents reported that the production field in which their firm operated at the foundation was the same as that of the companies for which the founder worked prior to foundation. Moreover, the activity in which the spinoff firm specialised at the time of foundation was the same as the activity the founder practised before going on his own: in fact, $75 \%$ of the firms performed the same function (most of which was sewing, drawing and cutting) that the founder exercised when he was still an employee. These results give support to Hypothesis 2, as discussed in Section 3.1.

The next issue relates to the decision of location of the 'new firms', as highlighted in Hypothesis 3 in Section 3.2. We find that: $78.5 \%$ of the 'new firms' that originated through a spinoff were located exactly in the same town as the 'parent firm' where the founder previously worked and $91.6 \%$ of them were located in the same town where the founder(s) lived. We conclude that Hypothesis 3 is also supported by our results.

Thank to this evidence, we sustain the idea that the agglomeration of firms mainly occurred through a series of spinoff firms whose founders decided to locate themselves near where they were previously employed and lived. Our results support Klepper's and Sorenson's view, as discussed in Section 3: the formation of spinoffs and the 'sticky' behaviours that induce spinning-off entrepreneurs to locate themselves in the cities in 
which already have contacts and where their families live generate the emergence of a cluster. These results show unequivocally that the experience and knowledge gained during working life is decisive when deciding to found a new firm. In a cluster, employees train and focus on specific activities and functions, which provide potential professional growth for the individuals. The technical specialisation and expertise represent an investment for the future of the employee: employees are able to start up a new business by exploiting the same activities in which they had developed their experience. Incumbent firms play the key role of incubators of knowledge development for the next generation of firms.

Putting together the results of Hypotheses 1-3, we are able to reconstruct the picture that represents the emergence of the Oleggio industrial district. Some firms settled in the Oleggio area at the end of the 1800. After World War 2, some of these firms grew and became large in size. Some of these specialised in swimwear activities to address the increased demand of these products. From these firms, employees learned the technical expertise in production and developed economic and social ties bounded in the Oleggio area, such as contacts with other firms, a relationship with local banks and relations with other specialised employees. A series of these employees decided to become self-employed, founding a new small firm, exploiting the knowledge they developed during the previous years of employment. Thus, a multiplicity of small-size and medium-size firms engaged in the production of swimwear and underwear products emerged, giving birth to the emergence of a cluster of firms, called the Oleggio industrial district. Moreover, our data show that the activities of these new firms typically took the forms of subcontracting and specialised in the same technical activity-field as where the founders had been employed. Firms mainly established themselves as subcontractors ( $94.7 \%$ of the surveyed firms) and there has been a very low tendency to move towards autonomous conditions over the years (only $22 \%$ of firms became autonomous producers in 2010).

We believe that our research gives an original contribution to the existing literature about clusters for various reasons. First, we give new evidence about the theories of spinoffs and social ties as a source for cluster emergence. Second, we present an unexplored case, which adds new evidence for comparative analyses of several micro-founded case studies to draw taxonomies on the emergence of clusters by identifying geographical-technological-sociological imperatives. Third, our case displays important peculiarities in comparison to the other well-known cases discussed in the literature: for example, the case of the automobile industry clustered in the Detroit region, as discussed by Klepper $(2007,2008,2010,2011)$, refers to all locations in Michigan within 100 miles of Detroit; the case of the tyre industry clustered in Ohio, as discussed by Buenstorf and Klepper $(2009,2010)$ and Klepper (2011), includes entrants located within 100 miles of Akron; and the semiconductor cluster in Silicon Valley, as discussed by Klepper $(2010,2011)$, is based in Santa Clara county, whose population in 1980 was equal to 1.3 million. The case we presented developed similar dynamics of agglomeration but on a very different scale of analysis. The Oleggio cluster developed on a much smaller scale than the abovementioned cases. In 1981, Oleggio had only 11 hundred inhabitants (and the whole cluster had approximately 23 hundred inhabitants). The Oleggio territory extends over an area of 37.79 square kilometres (i.e., 23.48 miles). We claim that our findings of the same dynamics but on a much smaller scale strengthen the scope of the effects of social ties and networks in geographically restricting the spinning off processes and consequent cluster emergence, thus reinforcing the argument about the 
location inertia and 'sticky' behaviours of entrepreneurs when they decide where to locate their firms.

To conclude, even if it is not the goal of this research, we believe that the argument of our analysis could also be useful for interpreting the reasons for the rapid decline of the Oleggio industrial district. We focus our attention on two factors: spinoffs and subcontracting. On the one hand, the results have shown that for the cluster generated through spinoff processes, most of the spinoffs came from failing or downsizing firms. We also discussed the process of knowledge inheritance that determines the prior knowledge of new firms when they enter the market. Some studies in the literature provide evidence that firm heritage drives firm performance (Andersson and Klepper, 2013). With regard to this, if the spinoffs are induced by the downsizing or failure of the parent firm, they are called 'pushed' spinoffs (Eriksson and Kuhn, 2006; Andersson and Klepper, 2013) or 'necessity' spinoffs (Buenstorf, 2009), whereas they are called 'pulled' spinoffs or 'opportunity' spinoffs if they are motivated by the exploration of new opportunities and the parent firm continues its activity. Eriksson and Kuhn (2006) Andersson and Klepper (2013), Dahl and Reichstein (2007) and Buenstorf (2009) find that when spinoffs are related to a situation of crisis for the parent firm, i.e., 'pushed' or 'necessity' spinoffs, their performance is worse and the probability of exit is higher. In line with these results, we interpret the crisis of the Oleggio cluster as a process of inheritance of unsuccessful routines through spinning off from downsizing parent firms. On the other hand, we already described the cluster as mainly formed by subcontracting relations among a few medium-large firms and many small-micro firms. What emerges from this picture is a situation of dependence of many small subcontracting firms on few medium-large firms, in line with the 'hub-and-spoke district' structure (Markusen, 1996; Guerrieri and Pietrobelli, 2004). In these clusters, interesting development processes may be envisaged: the presence of a large hub-firm with several activities and multiple linkages may foster the firms in the district to venture into new sectors and to diversify the activity of the cluster, stimulating the growth of the area (Guerrieri and Pietrobelli, 2004). In the same way, in these cases, when the hub-firm faces difficulties and recession, other satellite firms suffer. In the end, the fate of the cluster is linked to the fate of the hub-firms. The Oleggio cluster shows that most of the firms remained subcontractors, unable to move to an autonomous production with their own brands and autonomy. Most of the firms remained small (micro) in size. Many firms were laboratories with no employees, specialising in one activity that was typically outsourced by larger firms, with a few low-tech machineries in the founder's own house. There has been a total dependence of most of the firms in the cluster on the few medium-large firms since the beginning. We claim that the few medium-large leader firms created the cluster through spinoffs, determined the development of the cluster and, in the end, contributed to the decline of the cluster (Albino et al., 1998).

\section{Conclusions and policy implications}

In this paper, we discussed the spinoff theory of industry clustering and provided evidence about the idea that clusters emerge through the occurrence of three factors: the process of spinning off firms, knowledge inheritance through spinoffs and locational decisions' inertia. 
Individuals have their own history and experiences before becoming actual entrepreneurs: personal experiences, human capital and the inherited knowledge of the entrepreneur affect both the development of competences needed to be able to perceive opportunities, mobilise resources and organise a new business and what activity to exploit. Spinoffs represent a vehicle through which new opportunities are perceived and knowledge is inherited from one firm to another, bringing with them the memory, experience, tacit prior knowledge, routines and characteristics of the founder. Opportunity recognition and resources mobilisation are typically locally bounded by the social ties of the individuals: these factors are difficult to replicate outside the local community and outside the geographically bounded area of the cluster (Figueiredo et al., 2002). Moreover, individuals prefer to be located near where they live to remain close to family and friends because changing the region would break the existing social ties and connections, the development of new ties and connections would mean bearing costs from both pecuniary and emotional points of view. What emerges is a geographical inertia of the entrepreneurs to move elsewhere, even in presence of better production conditions. Following these lines of research, the role of spinoff formation and its linkages to the social ties of the founder combined with a hereditary theory of organisational competence may well explain cluster formation even without referring to any kinds of external economies.

Our analysis entails an original field study that provides microeconomic evidence of how the case of the swimwear district in Oleggio conform to these patterns. The typical entrepreneurs in this district began their experience as a seamstress (most of the entrepreneurs are women) in a medium-large size firm (such as Gagliardi, MGO or Gavinelli), where they acquired self-confidence and knowledge that - because of the desire to become self-employed or predominantly because of the risk of downsizing induced them to start a new business in the area adjacent to where they were employed and where they lived. Our data have confirmed the existence of a close link between the business focus of the new business and the professional backgrounds of the entrepreneurs.

We sustain the idea, then, that the combination of spinoffs, knowledge inheritance and locational decision inertia explain why clusters arise. These processes contribute to generating the critical mass of firms in the initial phase of cluster evolution, which subsequently may start external pecuniary and non-pecuniary effects in an agglomerated area. Spinoffs also contribute to cluster growth because of the trial-and-error experiences (typical in the primordial stages when uncertainty is high) they explore (Garavaglia, 2016), offering in this way a local learning mechanism that contributes to easing subsequent entrepreneurship and adapting to external shocks, innovation and change, as occurred in Hsinchu (Parker, 2010). When a critical mass of firms is reached, then, a selfsustaining process of agglomeration emerges, where the so-called external economies play a reinforcing role (e.g., in the Oleggio case, through the creation of consortium, the extension of infrastructures, the birth of related industries and the development of bank services). With respect to this, we conclude that the spinoff theory of cluster emergence is alternative but not mutually exclusive to the traditional explanations based on the existence of external economies.

This paper may have useful policy implications. If we acknowledge that clusters represent a vehicle of regional growth and if we believe that cluster formation is spurred by spinoffs, then policies aimed at regional development should focus on sustaining spinoff creation. This represents a change of direction with respect to the regional 
policies that concentrate on the development of external factors that encourage positive external economies. ${ }^{5}$ The question, then, is how to sustain spinoff creation.

First, it is important to create the conditions to foster self-employment. For example, courses for the resident population devoted to business administration and creating a business plan are needed to develop an 'entrepreneurial' attitude in people. Investing in education in a fundamental element for establishing a culture prone to starting new businesses and generating the competences that are the endogenous force of the local system, as in the case of the large San Jose cluster in Costa Rica (Parrilli and Sacchetti, 2008) and in Hsinchu in Taiwan (Parker, 2010). In addition, cooperations with local banks to provide financing to local firms would represent a key element for stimulating self-employment.

Second, it is crucial to focus on one or more successful businesses that can fertilise the local area through a process of offspring, which could be sustained. Policies that finance new ventures could give some priority criteria to projects that are related to the coherent professional background of the potential entrepreneur. Systems of protection of the idea of the spinoffs are required. Policies should also enhance collaboration between spinoffs and established firms. This is an important means for sustaining the initial stage of new firms and for creating a close network structure in the district.

Third, industrial development processes seem to be economic as well as social and cultural processes (Nuur and Laestadius, 2010): this is important to keep in mind if we believe that spinoff creation entails economic, social and cultural motivations. Local policies should focus on the co-development and co-evolution of these aspects: a context where both private and public actors share values represents a decisive element for sustaining the growth of the local area (Doepfer et al., 2016).

This work presents some limitations. Two further improvements may be interesting for future research. The first consists of the development of a more detailed dataset to run some econometric analyses to empirically sustain the idea of the paper. The second consists of the further development of the links between the forces behind spinoffs in the emergent stage of the cluster and the reasons behind the decline of firms in the maturity stage. As we discussed in Section 4.2, the relationship between 'pushed' (or 'necessity') spinoffs and the decline of the cluster deserves more research.

\section{References}

Acs, Z.J., Braunerhjelm, P., Audretsch, D.B. and Carlsson, B. (2009) 'The knowledge spillover theory of entrepreneurship', Small Business Economics, Vol. 32, No. 1, pp.15-30.

Albino, V., Garavelli, A.C. and Schiuma, G. (1998) 'Knowledge transfer and inter-firm relationships in industrial districts: the role of the leader firm', Technovation, Vol. 19, No. 1, pp.53-63.

Andersson, M. and Klepper, S. (2013) 'Characteristics and performance of new firms and spinoffs in Sweden', Industrial and Corporate Change, Vol. 22, No. 1, pp.245-280.

Audretsch, D. (2003) 'Innovation and spatial externalities', International Regional Science Review, Vol. 26, No. 2, pp.167-174.

Bagnasco, A. and Trigilia, C. (1984) (a cura di) Società e politica nelle aree di piccola impresa. Il caso di Bassano, Arsenale Editrice, Venezia.

Bagnasco, A. and Trigilia, C. (1985) (a cura di) Società e politica nelle aree di piccola impresa. Il caso della Valdelsa, Franco Angeli, Milano. 
Baici, E. and Mainini, C. (2003) Il distretto tessile-abbigliamento in provincia di Novara. Analisi e prospettive di sviluppo, Franco Angeli, Milano.

Becattini, G. (1987) Mercato e forze locali: il distretto industriale, Bologna, Il Mulino.

Becattini, G. (1989) 'Riflessioni sul distretto industriale marshalliano come concetto socio-economico', Stato e Mercato, Vol. 25, No. 1, pp.111-128.

Becattini, G. (1990) 'The Marshallian industrial district as a socio-economic concept', in Pyke, F., Becattini, G. and Sengenberger, W. (Eds.): Industrial Districts and Inter-Firm Cooperation in Italy, IILS, Geneva.

Becattini, G. (1997) 'Prato nel mondo che cambia (1954-1993)', in Prato storia di una città, Vol. 4, Firenze, Le Monnier.

Becattini, G. (2002) 'From Marshall to the Italian 'industrial districts'. A brief reconstruction', in Quadrio Curzio, A. and Fortis, M. (Eds.): Complexity and Industrial Clusters, Physica-Verlag, Heidelberg, New York.

Boschma, R.A. (2015) 'Do spinoff dynamics or agglomeration externalities drive industry clustering? A reappraisal of Steven Klepper's work', Industrial and Corporate Change, Vol. 24, No. 4, pp.859-873.

Boschma, R.A. and Wenting, R. (2007) 'The spatial evolution of the British automobile industry: does location matter?', Industrial and Corporate Change, Vol. 16, No. 2, pp.213-238.

Breschi, S. and Lissoni, F. (2001) 'Knowledge spillovers and local innovation systems: a critical survey', Industrial and Corporate Change, Vol. 10, No. 4, pp.975-1005.

Bresnahan, T., Gambardella, A. and Saxenian, A. (2001) "'Old economy' inputs for 'new economy' outcomes: cluster formation in the new Silicon Valleys', Industrial and Corporate Change, Vol. 10, No. 4, pp.835-860.

Brusco, S. (1989) Piccola impresa e distretti industriali, Rosenberg \& Sellier, Torino.

Buenstorf, G. (2007) 'Evolution on the shoulders of giants: entrepreneurship and firm survival in the German laser industry', Review of Industrial Organization, Vol. 30, No. 3, pp.179-202.

Buenstorf, G. (2009) 'Opportunity spinoffs and necessity spinoffs', International Journal of Entrepreneurial Venturing, Vol. 1, No. 1, pp.22-40.

Buenstorf, G. and Fornahl, D. (2009) 'B2C - bubble to cluster: the dot-com boom, spinoff entrepreneurship and regional agglomeration', Journal of Evolutionary Economics, Vol. 19, No. 3, pp.349-378.

Buenstorf, G. and Guenther, C. (2011) 'No place like home? Relocation, capabilities and firm survival in the German machine tool industry after World War II', Industrial and Corporate Change, Vol. 20, No. 1, pp.1-28.

Buenstorf, G. and Klepper, S. (2009) 'Heritage and agglomeration: the Akron tyre cluster revisited', The Economic Journal, Vol. 119, No. 537, pp.705-733.

Buenstorf, G. and Klepper, S. (2010) 'Why does entry cluster geographically? Evidence from the US tire industry', Journal of Urban Economics, Vol. 68, No. 2, pp.103-114.

Bun, M. and Makhloufi, A.E. (2007) 'Dynamic externalities, local industrial structure and economic development: panel data evidence for Morocco', Regional Studies, Vol. 41, No. 6, pp.823-837.

Dahl, M.S. and Reichstein, T. (2007) 'Are you experienced? Prior experience and the survival of new organizations', Industry and Innovation, Vol. 14, No. 5, pp.497-511.

Doepfer, B.C., Habisch, A., Pechlaner, H., Poppe, X-I. and Schwarz, C. (2016) 'Entrepreneurship, shared values and the region - assessing the conditions for regional social performance of entrepreneurial behaviour', International Journal of Innovation and Regional Development, Vol. 7, No. 1, pp.36-56.

Eriksson, T. and Kuhn, J.M. (2006) 'Firm spinoffs in Denmark 1981-2000 - patterns of entry and exit', International Journal of Industrial Organization, Vol. 24, No. 5, pp.1021-1040. 
Feldman, M.P. and Francis, J. (2003) 'Fortune favors the prepared region: the case of entrepreneurship and the Capitol region biotechnology cluster', European Planning Studies, Vol. 11, No. 7, pp.765-788.

Feldman, M.P. and Francis, J. (2004) 'Home grown solutions: fostering cluster formation', Economic Development Quarterly, Vol. 18, No. 2, pp.127-137.

Feldman, M.P., Francis, J. and Bercovitz, J. (2005) 'Creating a cluster while building a firm: entrepreneurs and the formation of industrial clusters', Regional Studies, Vol. 39, No. 1, pp.129-141.

Figueiredo, O., Guimaraes, P. and Woodward, D. (2002) 'Home-field advantage: location decisions of Portuguese entrepreneurs', Journal of Urban Economics, Vol. 52, No. 2, pp.341-361.

Franco, A.M. and Filson, D. (2006) 'Spin-outs: knowledge diffusion through employee mobility', RAND Journal of Economics, Vol. 37, No. 4, pp.841-860.

Garavaglia, C. (2016) 'Thinking about entry of firms: a theoretical discussion', International Business Research, Vol. 9, No. 2, pp.46-73.

Garavaglia, C. and Breschi, S. (2009) 'The co-evolution of entrepreneurship and clusters', in Fratesi, U. and Senn, L. (Eds.): Growth and Competitiveness in Innovative Regions: Balancing Internal and External Connections, Springer-Verlag, Berlin Heidelberg.

Glaeser, E.L., Kallal, H.D., Scheinkman, J.A. and Shleifer, A. (1992) 'Growth in cities', Journal of Political Economy, Vol. 100, No. 6, pp.1126-1152.

Gordon, I. and McCann, P. (2000) 'Industrial clusters: complexes, agglomeration and/or social networks?', Urban Studies, Vol. 37, No. 3, pp.513-532.

Granovetter, M. (1973) 'The strength of weak ties', American Journal of Sociology, Vol. 78, No. 6, pp.1360-1380.

Granovetter, M. (2005) 'The impact of social structure on economic outcomes', Journal of Economic Perspectives, Vol. 19, No. 1, pp.33-50.

Groot, S.P.T., de Groot, H.L.F. and Smit, M.J. (2014) 'Regional wage differences in the Netherlands: micro evidence on agglomeration externalities', Journal of Regional Science, Vol. 54, No. 3, pp.503-523.

Guerrieri, P. and Pietrobelli, C. (2004) 'Industrial districts' evolution and technological regimes: Italy and Taiwan', Technovation, Vol. 24, No. 11, pp.899-914.

Helfat, C. and Lieberman, M. (2002) 'The birth of capabilities: market entry and the importance of pre-history', Industrial and Corporate Change, Vol. 11, No. 4, pp.725-760.

Jacobs, J. (1969) The Economy of Cities, Random House, New York.

Klepper, S. (2007) 'Disagreements, spinoffs and the evolution of Detroit as the capital of the US automobile industry', Management Science, Vol. 53, No. 4, pp.616-631.

Klepper, S. (2008) The Geography of Organizational Knowledge, Mimeo, Carnegie Mellon University, Pittsburgh.

Klepper, S. (2010) 'The origin and growth of industry clusters: the making of Silicon Valley', Journal of Urban Economics, Vol. 67, No. 1, pp.15-32.

Klepper, S. (2011) 'Nano-economics, spinoffs and the wealth of regions', Small Business Economics, Vol. 37, No. 2, pp.141-154.

Klepper, S. and Sleeper, S. (2005) 'Entry by spinoffs', Management Science, Vol. 51, No. 8, pp.1291-1306.

Krugman, P. (1991a) 'Increasing returns and economic geography', Journal of Political Economy, Vol. 99, No. 3, pp.483-499.

Krugman, P. (1991b) Geography and Trade, MIT Press, Cambridge Mass.

Krugman, P. and Venables, A. (1990) 'Integration and the competitiveness of peripheral industry', in Bliss, C. and Braga de Macedo, J. (Eds.): Unity with Diversity in the European Community, Cambridge University Press, Cambridge. 
Lin, C.H., Tung, C.M. and Huang, C.T. (2006) 'Elucidating the industrial cluster effect from a system dynamics perspective', Technovation, Vol. 26, No. 4, pp.473-482.

Lucas, R.E. (1988) 'On the mechanics of economic development', Journal of Monetary Economics, Vol. 22, No. 1, pp.3-42.

Mainini, C. (2003) Il distretto tessile di Oleggio e Varallo Pombia, Slide Presentation, Università degli Studi del Piemonte Orientale Amedeo Avogadro, Novara.

Markusen, A. (1996) 'Sticky places in slippery space: a typology of industrial districts', Economic Geography, Vol. 72, No. 3, pp.293-313.

Marshall, A. (1919) Industry and Trade, MacMillan, London.

Marshall, A. (1920) Principles of Economics, MacMillan, London.

Molina-Morales, F.X. and Martínez-Fernández, M.T (2008) 'Shared resources in industrial districts: information, know-how and institutions in the Spanish tile industry', International Regional Science Review, Vol. 31, No. 1, pp.35-61.

Nuur, C. and Laestadius, S. (2010) 'Development in peripheral regions: case studies in Sweden', European Urban and Regional Studies, Vol. 17, No. 3, pp.293-307.

Ottaviano, G. and Puga, D. (1998) 'Agglomeration in the global economy: a survey of the 'new economic geography”, World Economy, Vol. 21, No. 6, pp.707-731.

Ottaviano, G. and Thisse, J.F. (2001) 'On economic geography in economic theory: increasing returns and pecuniary externalities', Journal of Economic Geography, Vol. 1, No. 2, pp.153-179.

Ottaviano, G. and Thisse, J.F. (2004) New Economic Geography: What about the N?, CORE Working Paper, January.

Paniccia, I. (2002) Industrial Districts. Evolution and Competitiveness in Italian Firms, Edward Elgar, Cheltenham.

Parker, R. (2010) 'Evolution and change in industrial clusters: an analysis of Hsinchu and Sophia Antipolis', European Urban and Regional Studies, Vol. 17, No. 3, pp.245-260.

Parrilli, M.D. and Sacchetti, S. (2008) 'Linking learning with governance in networks and clusters: key issues for analysis and policy', Entrepreneurship \& Regional Development. An International Journal, Vol. 20, No. 4, pp.387-408.

Patrucco, P. (2005) 'The emergence of technology systems: knowledge production and distribution in the case of Emilian plastic district', Cambridge Journal of Economics, Vol. 29, No. 1, pp.37-56.

Porter, M. (1990) The Competitive Advantage of Nations, Free Press, New York.

Puga, D. and Venables, A.J. (1996) The Spread of Industry: Spatial Agglomeration in Economic Development, CEPR Discussion Paper Series, 1354, London

Pyke, F. and Sengenberger, W. (1990) 'Introduction', in Pyke, F., Becattini, G. and Sengenberger, W. (Eds.): Industrial Districts and Inter-Firm Co-Operation in Italy, pp.1-9, International Institute for Labour Studies, Geneva.

Romer, P.M. (1996) 'Increasing returns and long-run growth', Journal of Political Economy, Vol. 94, No. 5, pp.1002-1037.

Rosenthal, S.S. and Strange, W.C. (2004) 'Evidence on the nature and sources of agglomeration economies', in Henderson, J.V. and Thisse, J.F. (Eds.): Handbook of Regional and Urban Economics, North Holland, Elsevier, Amsterdam.

Saxenian, A. (1983) 'The urban contradictions of Silicon Valley: regional growth and the restructuring of the semiconductor industry', International Journal of Urban and Regional Research, Vol. 7, No. 2, pp.237-262.

Scott, A.J. (1988) 'Flexible production systems and regional development: the rise of new industrial spaces in North America and Western Europe', International Journal of Urban and Regional Research, Vol. 12, No. 2, pp.171-186. 
Sforzi, F. (1990) 'The quantitative importance of Marshallian industrial districts in the Italian economy', in Pyke, F., Becattini, G. and Sengenberger, W. (Eds.): Industrial Districts and Inter-Firm Co-operation in Italy, pp.1-9, International Institute for Labour Studies, Geneva.

Sorenson, O. (2003) 'Social networks and industrial geography', Journal of Evolutionary Economics, Vol. 13, pp.513-527.

Sorenson, O. and Audia, P. (2000) 'The social structure of entrepreneurial activity: geographic concentration of footwear production in the United States, 1940-1989', American Journal of Sociology, Vol. 106, No. 2, pp.424-462.

Spithoven, A. (2015) 'Technology transfer as a driver for location of R\&D active firms on science parks', International Journal of Innovation and Regional Development, Vol. 6, No. 1, pp.80-101.

Stuart, T. and Sorenson, O. (2003) 'The geography of opportunity: spatial heterogeneity in founding rates and the performance of biotechnology firms', Research Policy, Vol. 32, No. 2, pp.229-253.

Tappi, D. (2005) 'Cluster, adaptation and extroversion: a cognitive entrepreneurial analysis of the Marche music cluster', European Urban and Regional Studies, Vol. 12, No. 3, pp.289-307.

\section{Notes}

1 In contrast, according to Jacobs (1969) knowledge spillovers occur across sectors.

2 The argument about spinoff, prior knowledge and experience may also refer to public institutions, universities and research centres as incubators of new spinning-off firms (Bresnahan et al., 2001; Feldman et al., 2005).

3 Agrate Conturbia, Barengo, Bellinzago Novarese, Borgo Ticino, Castelletto Sopra Ticino, Divignano, Marano Ticino, Mezzomerico, Momo, Oleggio, Pombia, Vaprio d'Agogna and Varallo Pombia. The seven municipalities registered 26.881 inhabitants in 1996.

4 (Im) is ratio between the weight of the local manufacturing industry workers to the national total. (Id) compares the weight of the units' local manufacturing compared to the population living with the weight of units' manufacturing to the national population residing in Italy. (Is) is the relationship between the local staff in a given sector and those employed in the same industry at national level. (Ps) is the relationship between the local staff in the relevant specialisation and total employment in activities' within the manufacturing system. (Pi) shows the weight of those employed in local manufacturing for the industry in highly specialised units with fewer than 200 employees to the total local employment in that sector.

5 Note that Oleggio is close to the Malpensa airport and the recent logistic and service centres in the Malpensa area and is close to the 'new' train intermodal station in Novara. 